\title{
Teaching young people to learn to swim
}

\section{A community effort}

\section{SALLY ROBERTSON}

\section{KEY POINTS}

- Learning to swim is crucial for water safety. Schools in this survey saw swimming as an important skill for students to develop.

- In many areas, developing swimming skills was a community endeavour, with schools involving the local community and drawing on community resources for their learning-to-swim programmes.

- Many schools share their pools or use council or community pools for lessons. About a third of schools also made use of external swimming instructors, although most swimming teaching is done by classroom teachers.

- Half the schools surveyed needed help with funding, often drawing on community fundraising to maintain their learningto-swim programmes.

- Some students may need extra support to learn to swim-for example, new migrants who have not spent much time around water, or students whose religious beliefs require modest dress. 


\begin{abstract}
Despite New Zealand being a water-loving nation, we do not have a good track record when it comes to water safety. Last year the New Zealand Council for Educational Research surveyed schools to gather information about their pools and aquatic education programmes for Water Safety New Zealand. This article looks at some of the findings from this survey. In particular it focuses on the ways in which communities were working to help ensure that young people were learning to swim, and discusses some of the benefits and challenges of community involvement.
\end{abstract}

\section{Introduction}

Despite New Zealand being a water-loving nation, we do not have a good track record when it comes to water safety. Over the last five years, 114 New Zealanders have drowned each year on average; this is one of the worst drowning rates in the developed world (Water Safety New Zealand, 2010b). In 2008, New Zealand had twice as many people drown per capita as Australia (Water Safety New Zealand, 2009). Recent data also show that children's swimming ability has been decreasing, with worryingly low percentages of students being able to perform basic swimming tasks that are essential for water safety:

In 2008, just one in five 10-year-olds can swim 200m-the benchmark Water Safety New Zealand considers necessary to swim and survive in the water. (Water Safety New

Zealand, 2008, p. 1)

The message in advertisements from Water Safety New Zealand (WSNZ) is clear: "Learning to swim means learning to survive." What then are schools doing to prepare students to be safe around water?

Last year, WSNZ contracted the New Zealand Council for Educational Research (NZCER) to conduct a survey of schools and create a database containing information about schools' aquatic education programmes and pools. WSNZ wanted to have an accurate analysis of the issues that schools were facing in order to be more strategic in their work and help improve learning to swim in New Zealand.

The survey covered 2,553 state, state-integrated, private, special and kura kaupapa Māori schools, both primary and secondary. We used a number of communication methods in order to generate the most complete database possible for WSNZ. First we contacted schools by email, giving a link to the online version of the survey. We then sent reminder emails and paper versions of the survey to schools that did not respond initially. Finally, we conducted phone interviews with schools that had still not responded. In total, we obtained a response rate of 99 percent, suggesting that this topic is important to schools.

\section{The findings}

The survey contained mainly multiple-choice questions, but schools were also given the opportunity to make additional comments at the end. A fifth of all of these comments related to the importance of learning to swim. For example, one school leader said: "We think it is vital that young New Zealanders learn to swim and be safe in the water." Another said: "[learning to swim is] one of the few things we teach that can actually save a child's life".

Another strong theme that emerged from these comments was the idea that it was a shared community responsibility to teach young people to swim. Many schools saw pools as a community resource and were looking for community solutions to support them to offer learning-to-swim programmes. Given the high costs involved in teaching students to swim, community involvement was important to many schools.

The findings presented below highlight ways in which communities were working to help ensure that young people were learning to swim. Community-based strategies used by many schools included the sharing of pools, sharing swimming teaching, and community funding. Some of the benefits as well as challenges of community involvement are also discussed.

\section{Sharing of pools}

Of the schools that offered learning-to-swim programmes, 59 percent used their own pools. However, using community resources was also common, with 
35 percent using council pools and 15 percent using a community pool (note that some schools used more than one type of pool).

Schools acknowledged many benefits of using council or community pools, particularly financial and time benefits as they did not have to maintain a pool of their own. Some schools were able to use council pools free of charge.

Another benefit of using council and community pools was that this allowed schools access to a wider variety of pools. The majority of schools' pools were 15 metres long, but council and community pools were usually deeper and longer, meaning that students could practise different skills. Council and community pools were also more likely to be indoors, meaning swimming programmes were not so weather dependent. Of the schools we surveyed, only 12 percent had indoor school pools. One school leader stated:

The use of the council pool allows us the depth ... for the varying levels of ability. It is a cost-saving factor [and is an] indoor facility that allows the programme to not [be] interrupted.

Some schools mentioned difficulties they faced when using council or community pools. These challenges included expensive entry fees and high demands on the pool, meaning that it could be hard to fit school lessons in.

A significant proportion of schools also shared another school's pool for their learning-to-swim programmes. Of the schools that had pools, around a quarter were currently sharing their pool with other local schools or groups. The most commonly mentioned benefit was the financial savings gained from sharing costs.

Comments from schools included:

Each February we co-operate with another small local school and rent their pool for a minimal fee. We are grateful that we can share these resources.

[It] would be better if two schools share a very good pool, instead of having two not-so-good pools each.

Some schools had forged innovative collaborations; for example, one school leader stated:

We arranged a joint venture with a swim school to build a pool on our school property at no cost to us. We share the pool with the swim school.

\section{Access to pools is one aspect of providing swimming programmes, but students also need to have access to capable swimming teachers.}

It appears that there is more potential for sharing in the future as almost a fifth of schools with pools said they would be prepared to share their pool (and were not currently doing this).

\section{Sharing swimming teaching}

Access to pools is one aspect of providing swimming programmes, but students also need to have access to capable swimming teachers. While the majority of learning-to-swim programmes were taught by classroom teachers, over a third were taught by external swimming instructors, and around 10 percent by parents. Some schools used a combination of people. Primary schools most often used general classroom teachers while secondary schools were more likely to use specialised support (i.e., physical education teachers).

Many schools thought it was valuable to use external swimming instructors with specialised skills. Cost was the main barrier to using external swimming instructors. Some schools used parents who had been trained in teaching swimming. Other parents and community members who did not have particular swimming skills could help out in other ways, such as through water testing. Many schools also saw the benefits of parents teaching their children to swim or taking them to private swimming lessons outside of school time, as one school leader stated:

It can't be the sole responsibility of the school-it's never enough for kids to maintain the skills. Parents also have to take responsibility.

Around 20 percent of schools that offered learningto-swim programmes stated that they would like help finding external instructors to teach their swimming programmes. A similar number said they needed more teaching assistants. Ten percent said they would like more parent help.

Some schools preferred having classroom teachers teach their learning-to-swim programmes. For example, one principal said:

My only concern about using someone else's facility is the instructors are not always consistent-because of rosters and things. Children who have the same instructor for three weeks seem to make more progress.

The training of school staff members was also an issue for many schools. Just under a quarter of schools that offered learning-to-swim programmes reported that none of their teachers had been trained in the last five years. Almost half of those offering learning-to-swim programmes said they needed help training staff from their own school. Some of the barriers to accessing staff training were the costs involved, the demands on teachers' time and sourcing training for those in isolated locations. 


\section{Funding sources}

Funding was a big challenge for schools, and again an area where community involvement was important. In the survey schools were asked if they needed assistance with their learning-to-swim programmes. Over half of schools that offered learning-to-swim programmes identified that they needed assistance with funding for their programmes or pools. In particular, schools often mentioned the high costs associated with pool maintenance, transport costs, pool hire and swimming instructors. Over a third of schools stated that they needed assistance maintaining or upgrading the pool they used. Almost 30 percent said they needed more or better water safety equipment/material, and a quarter said they needed help with transport options to a pool.

Some schools felt the government should contribute more because of the importance of learning to swim and because teaching learning to swim is compulsory at primary level. The New Zealand Curriculum says:

$\ldots$ it is expected that all students will have had opportunities to learn basic aquatic skills by the end of Year 6 ... (Ministry of Education, 2007, p. 22)

One school commented:

The limiting factor is the cost of maintaining your own school pool. There needs to be more government funding to keep these open so students have access. Our poor record of drownings indicates that this should be a priority.

To address the funding need, communities were often involved in fundraising for school pools (for example, through school galas). One common fundraiser was for schools to hire pool keys out to community members over the summer holidays. Some schools came up with variations on this concept, with one school leader stating:

A fundraising idea from students was to open the pool at lunch time and children pay 50 cents for a swim.

Many schools also received financial support from a number of different community sources, including city and district councils, licensing trusts, church groups, private businesses and sports trusts. The financial contributions from community groups and organisations appear to be essential in enabling some schools to provide learning-to-swim programmes.

\section{Swimming for everyone}

It is important that learning-to-swim programmes are appropriate for all students in the school community. A few school leaders talked about cultural reasons why some students might not feel comfortable swimming. For example, due to religious beliefs, some Muslim students may need to dress modestly. Solutions included gaining access to a private pool, running separate sessions for male and female students and relaxing school policies on what students could wear when swimming.

A few school leaders talked about the importance of providing extra support to students who may not have grown up around the water. For example, some talked about new migrants who have had no opportunities to learn to swim previously:

Swimming skills are hugely important for our students

who are mainly new immigrants with little experience of

beaches and swimming.

Several schools thought that swimming certificates should be developed to encourage children to learn to swim. Some mentioned that they had designed their own set of certificates for this purpose. Further details about certificates are included in the useful resources section at the end of this article.

\section{Conclusion}

Teaching young people to learn to swim is essential if we are to improve our water safety record. Almost all schools recognised the importance of teaching their students to learn to swim. For example, one school principal stated: "Learning to swim in NZ is essential, and in my opinion is NOT NEGOTIABLE."

It appears that many schools see a community approach as an effective way of achieving this. One school described their pool as "a community focal point". Schools were sharing resources, involving parents and doing community fundraising, often in innovative ways.

We acknowledge that schools have many competing demands for their funding. The data from this survey suggest that there could be benefits for other schools in further developing community approaches. It is clear that schools are evolving creative solutions to support their students to learn to swim that involve working with the local community and accessing a wide range of funding sources.

\section{Acknowledgements}

I would like to thank Sally Boyd, Rachel Bolstad and Rose Hipkins for their helpful feedback on drafts of this article.

\section{Useful resources}

WSNZ has many useful resources on their website: www. wsnz.org.nz. These include resources in te reo Māori.

Their vision is that "Everyone in New Zealand will have the water safe skills and behaviours necessary to use and enjoy the water safely" (Water Safety New Zealand, 2010a). 
Swimming New Zealand sells swimming certificates online from http://www.swimmingnz.org.nz/education/ for-swim-teachers/resources/certificates/. There are SwimStart certificates for each of the five levels of learnto-swim development and SwimSkills certificates, which are awarded when students learn particular strokes and swim certain distances.

\section{References}

Ministry of Education. (2007). The New Zealand curriculum.

Wellington: Learning Media.

Water Safety New Zealand. (2008). Kiwi kids'swim skills are sinking fast. Wellington: Author.
Water Safety New Zealand. (2009). 2008 drowning report.

Retrieved 24 May 2010, from http://www.watersafety.org. nz/assets/newsAndMediaReleases/Year_in_Review_2008. pdf

Water Safety New Zealand. (2010a). About us. Retrieved 24 May 2010, from http://www.watersafety.org.nz/about-us/ Water Safety New Zealand. (2010b). NZ drowning statistics.

Retrieved 24 May 2010, from http://www.watersafety.org.nz/

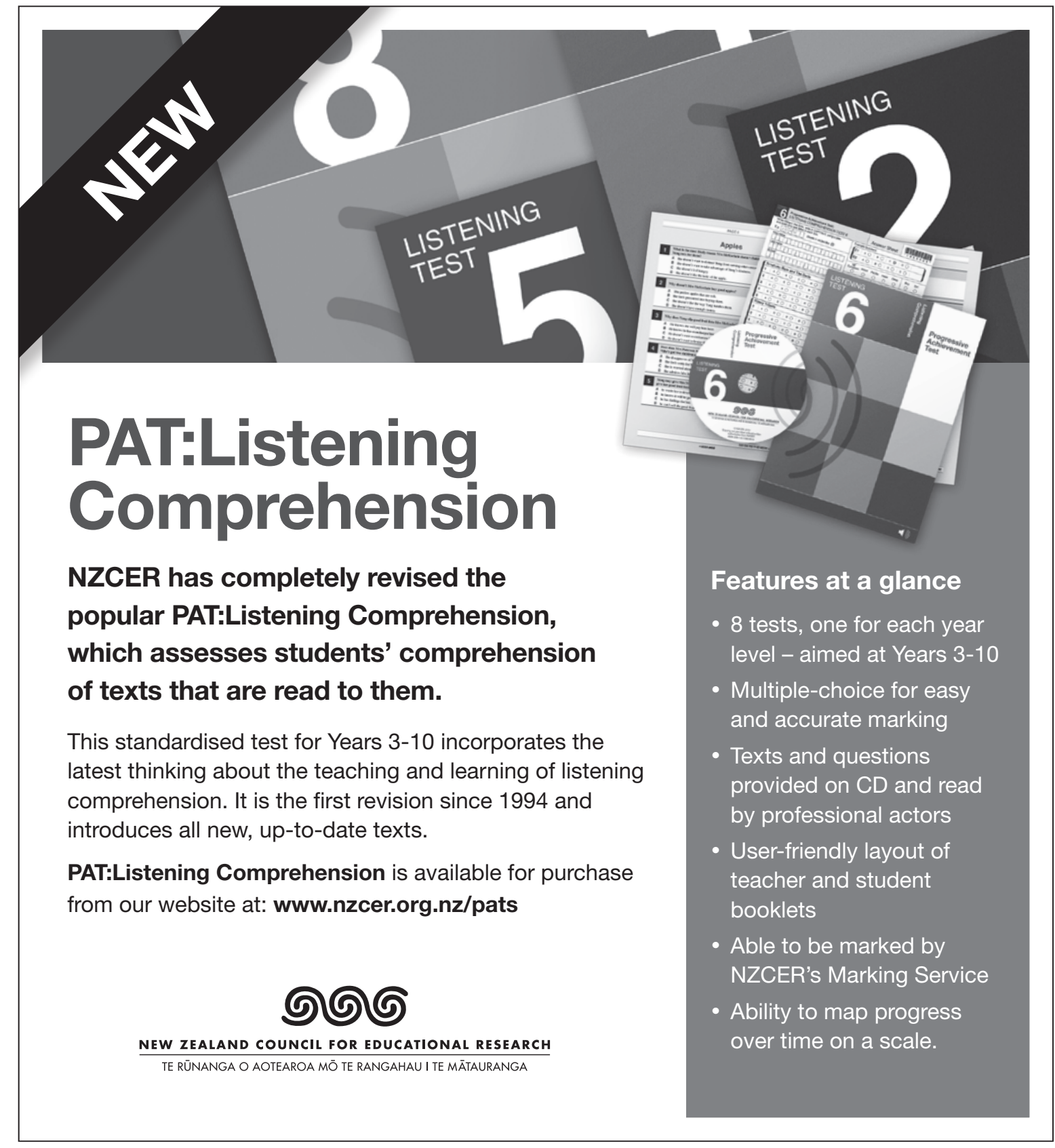

